\title{
South America (2019)
}

\author{
Marcos Nelio Mollar*
}

In 2019, disaster risk reduction strategies continued being developed and implemented by national, sub regional, regional and intergovernmental organisations in the Americas, through their policies and programmes, according to the 2030 Agenda, the Sendai Framework, the regional strategies and plans of Regional Platform for Disaster Risk Reduction and other relevant international agendas.

Organization of American States (oAs)

Concerning the activities of Organization of American States (OAS), in June 2019 the OAS General Assembly adopted its resolution 2939, related to 'Advancing Hemispheric Initiatives on Integral Development'. 'Through this resolution, the General Assembly, regarding the strategic line: 'strengthening the implementation of sustainable development goals in accordance with the inter-American program for sustainable development (PIDS) 2016-2O21', instructed the Executive Secretariat for Integral Development (SEDI) to present to the Inter-American Council for Integral Development (CIDI), before the end of 2019, a proposal to streamline and strengthen the oAs' tools and entities that support cooperation and dialogue on disaster risk management in the Americas, taking into account the objectives and strategic actions of the PIDS. Such proposal should be developed in coordination with the relevant areas of the OAs and the corresponding organs and entities of the inter-American system, and be aligned with global efforts on these topics according to national and regional contexts, and its potential implementation will be subject to the availability of financial resources in the program budget of the organisation and other resources. The proposal should be focused on the exchange of best practices, experiences, and lessons learned in thematic areas such as: the design of public policies to improve disaster risk management, institutional strengthening, and capacity building, as well as those seeking to improve medium- and long-term recovery and reconstruction efforts in the hemisphere. In addition, SEDI should present an annual report to a joint session of the CIDI and the

* Professor of International Law, University of Buenos Aires and Universidad Católica Argentina.

1 OAS-GA Res 2939 (27 June 2019), OAS GA/RES. 2939 (XLIX-O/19).

(C) MARCOS NELIO MOLLAR, 2021 | DOI:10.1163/26662531_00201_022

This is an open access chapter distributed under the terms of the GC BY-NC 4.Plicense. 2 , com $04 / 26 / 2023$ 11:55:29AM 
Permanent Council on the activities and achievements of the OAS on disaster risk management, including the cooperation and coordination among different stakeholders working on this area in the Americas.

Furthermore, resolution 2939 instructed the SEDI to conduct - in coordination with the relevant areas of the OAS and the Inter-American system, in particular the Secretariat for Multidimensional Security (sMs) and the Committee on Hemispheric Security ( $\mathrm{CSH}$ - a study, within available resources, of existing tools and entities established within the inter-American system to address natural disaster response and to report such findings to a joint meeting of the Permanent Council and CIDI by the end of 2019. The study should include: (1) the future structure, responsibilities, and membership of the Inter-American Committee for Natural Disaster Reduction (IACNDR); (2) the future of the Inter-American Emergency Aid Fund (FONDEM), specifically whether it should be abolished or replaced with an instrument that can facilitate the orderly and timely transfer of post-disaster assistance between member states and affected countries; (3) the future of the Inter-American Convention on the Facilitation of Disaster Assistance; (4) the Inter-American Network for Disaster Mitigation (INDM); and (5) the experiences of member states that have been affected in engaging with these entities.

OAS General Assembly, through its resolution 2945 regarding 'Advancing Hemispheric Security: a Multidimensional Approach,'2 decided to continue strengthening the hemispheric security cooperation by addressing traditional threats, new threats and vulnerabilities, concerns, and other challenges that have been identified and characterized by their multidimensionality and complexity, such as Humanitarian Assistance and Disaster Response.

In this regard, oAs General Assembly instructed the Permanent Council and CIDI to convene, during the first half of 2020, a joint meeting to be attended by the national coordinating authorities for natural disaster management in OAS member states, the members of the Inter-American Committee on Natural Disaster Reduction (IACNDR), and representatives of the Department of Public Security (DPS) of the Secretariat for Multidimensional Security (sMs), the Inter-American Network for Disaster Mitigation (INDM) of SEDI, the Inter-American Defense Board (IADB), regional disaster management agencies - Andean Committee for Disaster Prevention and Assistance (CAPRADE), Caribbean Disaster Emergency Management Agency (CDEMA), and Coordination Centre for the Prevention of Natural Disasters in Central America (CEPREDENAC), - and the United Nations Office for the Coordination

2 OAS-GA Res 2945 (28 June 2O19), OAS GA/RES. 2945 (XLIX-O/19). 
of Humanitarian Affairs (OCHA), to consider, the 'Inter-American Plan for Disaster Prevention and Response and the Coordination of Humanitarian Assistance,' endorsed by the General Assembly in 2012, the Inter-American Emergency Aid Fund (FONDEM, 1965), the Inter- American Convention to Facilitate Disaster Assistance (IACFDA, 1991), and the IACNDR (1999).

OAS General Assembly also encouraged the states party to the Inter-American Convention to Facilitate Disaster Assistance (IACFDA) to consider the future of the convention and instructed the General Secretariat, through the SMS and SEDI, to complete the development of a Model National Strategy on the Protection of Critical Infrastructure in the event of Natural Disasters, and to present a draft to member states for consideration during the second half of 2019.

In addition, OAS General Assembly endorsed the five recommendations developed by the CSH to support the efforts of OAS member states in addressing the security implications of climate change and promoting natural disaster risk reduction and mitigation, namely: a) preparedness for resolution of resource-driven conflict; b) development of rights-based prediction and prevention measures; c) emphasis on policy harmonization; d) investment in resilience promotion; and, e) prioritization of risk-mitigation measures. Moreover, instructed the General Secretariat to provide, subject to available resources, technical and administrative assistance to support member states in their efforts to implement the recommendations developed by the $\mathrm{CSH}$ to address the security implications of climate change.

\section{2 \\ Activities of the United Nations Office for Disaster Risk Reduction (UNDRR) related to the Americas}

In 2019, UNDRR worked, in the South America Region, with several regional organizations to support the development and implementation of regional disaster risk reduction strategies and plans. These organizations included the Andean Committee for Disaster Prevention and Assistance of the Andean Community of Nations, and the Meeting of Ministers and High-level Authorities on Comprehensive Disaster Risk Management of the Southern Common Market. Strong engagement of UNDRR in the process ensured that the plan was well aligned with the Sendai Framework.

In the Americas, UNDRR worked with the UN Sustainable Development Group for Latin America and the Caribbean through issue-based coalitions (IBCS), which act as regional task forces to facilitate cooperation and response to cross-cutting challenges in the region. UNDRR co-chairs two IBCs in the region: The Regional Inter-Agency Resilience Group, aimed at enhancing 
coordination of disaster risk reduction efforts among UN agencies in the region, and the Climate Change and Resilience гвс. Through engagement in these coalitions in 2019, UNDRR successfully ensured a disaster risk reduction agenda coherent with climate change action in countries across the Andean region and the southern cone of South America. In addition, UNDRR has engaged stakeholders in the region to support and advocate for the implementation of a risk-informed 2030 Agenda and enhance climate change adaptation and disaster risk reduction based on risk knowledge and evidence. ${ }^{3}$

National and local disaster risk reduction strategies are essential for implementing and monitoring a country's risk reduction priorities. In 2019, working with local, national and regional organizations, together with UN Resident Coordinators and Country Teams, UNDRR supported the development and revision of disaster risk reduction strategies, as well as the monitoring of their implementation. These strategies set implementation milestones established key roles and responsibilities of government and non-government actors and identified technical and financial resources. ${ }^{4}$

By the end of 2019, 8 countries in the Americas and the Caribbean Region had finalized and made publicly available a national disaster risk reduction strategy, and 17 others were in the process of formal approval. The status of national disaster risk reduction strategies in these countries was then assessed to inform the nature of technical assistance that should be provided by UNDRR in 2020. In 2019, the Brazilian municipalities of São José do Rio Preto, and Vinhedo validated their local disaster risk reduction action plans. UNDRR also worked with the UN Educational, Scientific and Cultural Organization in the city of Cusco (Peru) to develop a local disaster risk reduction strategy, with a focus on heritage protection. ${ }^{5}$

In 2019, member states of Andean Community agreed on the importance of developing a tool that allows them to have integrated - in a methodological, planned and programmatic way - the objectives, actions and goals of the

3 UNDRR, Annual Report (2019) 3 .

4 Ibid., 33 .

5 Ibid., 35 .

6 Andean Community (CAN) is an international organization that has various bodies and institutions that make up the Andean Integration System (SAI) whose objective is to achieve an integral, balanced and autonomous development through Andean integration, with a projection towards a South American and Latin American integration. Bolivia, Colombia, Ecuador 
Andean Strategy for Disaster Risk Management (EAGRD). ${ }^{7}$ Consequently, the 'Implementation Plan of the Andean Strategy for Disaster Risk Management (EAGRD) 2019-2030' was adopted. This document identifies institutions responsible for implementing goals and actions of EAGRD and for evaluating and monitoring their progress and achievements. ${ }^{8}$

\section{$4 \quad$ Southern Common Market (MERCOS UR $)^{9}$}

In the sixteenth Ordinary Meeting of Ministries and High-level Authorities on Comprehensive Disaster Risk Management of MERCosUr (RMAGIR), on 13 March 2019, national delegations signed the text of the 'Strategy for Disaster Risk Management for MERCosUR's member states' 10 and signed the 'Arrangement for the creation of Hydrometeorological Technical Services Commission' and presented its Action Plan.

In 2019, national delegations at RMAGIR continued with discussions related to mechanisms of cooperation with CAPRADE (Andean Community) and other regional blocks; the creation of mechanisms of shared disaster risk management between border cities; Biennial Action Plan of RMAGIR (2019-2020) and disaster risk management and public-private partnerships.

\section{5}

\section{National Initiatives}

White Helmets - the agency of the Ministry of Foreign Affairs and Worship of Argentinian Republic - continued designing and implementing humanitarian assistance and strengthened its role as the international focal point for the UN Office for Disaster Risk Reduction and the International Search and Rescue Advisory Group (INSARAG) of the UN Office for the Coordination of Humanitarian Affairs (OCHA).

and Peru are Member States of the Andean Community <http://www.comunidadandina .org/> last accessed (as any subsequent URL) on 20 July 2020.

$7 \quad$ Approved by Decision 819 of Andean Council of Ministries of Foreign Affairs (9 May 2017).

8 Implementation Plan of the Andean Strategy for Disaster Risk Management (EAGRD) 2019-2030 <http://www.comunidadandina.org/StaticFiles/Temas/Atencion PrevencionDesastres/Plan.pdf $>$.

9 Mercosur is a South American trade bloc comprised of Argentina, Brazil, Paraguay, Uruguay and Venezuela.

10 Whose text had been approved during fifteenth Ordinary Meeting of Ministries and High-level Authorities on Comprehensive Disaster Risk Management of MERCosur (RMAGIR), held in Buenos Aires on 13 March 2019. 
In 2019, the White Helmets implemented humanitarian assistance in Mozambique (May-June 2019), coordinated operational issues for assistance with the Plurinational State of Bolivia due to wildfire in the Amazon (August-October 2019) and pre-positioning of supplies activities in Panamá to Colombia (April 2019). ${ }^{11}$ Also, the President of the White Helmets was appointed to preside the Americas Regional Group of International Search and Rescue Advisory Group (INSARAG).

The White Helmets was also designed to host of the IX Meeting of International Mechanisms for Humanitarian Assistance (MIAH), held in Buenos Aires, 12,13 and 14June 2019. During this meeting, participants discussed human mobility in the context of humanitarian crisis and the strengthening of mechanisms of cooperation for humanitarian assistance. They approved the 'Buenos Aires Declaration', that promote mechanisms to reduce risk disasters and provide a quick and effective response.

Furthermore, the White Helmets signed a Memoranda of Understanding (MOUs) about Risk Disaster Management and Humanitarian Assistance with Operational Center of Emergency of Dominican Republic (21 March 2019) and a MOUs with the UN Office of Coordination for Humanitarian Affairs (OCHA) in order to promote the comprehensive management of risk reduction and reduction of vulnerabilities of communities (12 June 2019).

In addition, it could be mentioned how national governments adopted plans and strategies aligned Sendai Framework for Disaster Risk Reduction 20152030. In Chile, the National Emergency Office of Interior Ministry (ONEMI) elaborated the 'Strategy Plan ONEMI 2019-2023', to facilitate actions to the management of the risk of disaster. ${ }^{12}$ In Uruguay, the National Emergencies and Reduction Risks Board approved the National Politics of Comprehensive Management of Emergencies and Disaster Risks in Uruguay (2019-2030) (24 September 2019).

11 White Helmets Report 2016-2019, available at <https://cancilleria.gob.ar/userfiles/2020/ comision-cascos-blancos-2016-2019_.pdf>.

12 'Strategy Plan ONEMI 2019-2023', available at <https://siac.onemi.gov.cl/documentos/ TEMP/PlanEstrategicoInstitucional_5.pdf >. 